\title{
Preparation of the Inclusion Complex-Type Nonlinear Optical Polymer
}

\author{
Li-Fen Wang, Jyun-Wun Chen, and Jyun-Wei Chen \\ Department of Applied Chemistry and Material Science, Fooyin University, 151 Chin-Hsueh Road Ta-Liao Hsiang, Kaohsiung, \\ 83102, Taiwan \\ Correspondence should be addressed to Li-Fen Wang; sc112@mail.fy.edu.tw
}

Received 29 June 2012; Accepted 6 September 2012

Academic Editor: Stéphane Viel

Copyright (C) 2013 Li-Fen Wang et al. This is an open access article distributed under the Creative Commons Attribution License, which permits unrestricted use, distribution, and reproduction in any medium, provided the original work is properly cited.

\begin{abstract}
This study uses the inclusion complex method to import nonlinear optical (NLO) chromophores, disperse red1 (DR1), and spiropyran (SP), into the $\gamma$-CD cavity of the $\gamma$-cyclodextrin polymer ( $\gamma$-CDP) to prepare orderly aligned nonphotocontrollable and photocontrollable nonlinear optical polymers. Calculations support the ultraviolet/visible analyses and suggest the formation of the $1: 2 \mathrm{DR} 1 / \gamma$-CDP and $1: 2 \mathrm{SP} / \gamma$-CDP inclusion complexes. Upon complexation, the DR1 and SP molecules are free to align themselves along an applied electric field and show high order parameters of approximately 0.48 and 0.20 , respectively. Reversible photochromic reactions exhibit that the $\mathrm{SP} / \gamma$-CDP complex still retains the photochromic properties following corona poling.
\end{abstract}

\section{Introduction}

Nonlinear optical (NLO) material possessing optical modulation capabilities including changing optical phase, changing optical frequency, or coupling more than two light beams to increase or decrease frequency has recently become the most significant development goal for photonic devices $[1,2]$. Through the development of NLO materials, photonics can be used as a future carrier of information and overcome transmission bottlenecks for current electronic transmission methods, including the resistive losses that occur with electrons moving through metal wires as the frequency of information increases [3].

Although general NLO organic molecules have excellent NLO properties, their commercial applications are limited because of the difficulty of their processing. By combining NLO molecules with polymers, the high NLO susceptibility, fast response time, low dielectric constant, small dispersion in refractive index, structural flexibility, and ease of material processing have brought NLO polymers to the forefront of NLO research [4]. NLO polymers can be divided into guest/host polymer [5-7] and covalently linked polymers (side- and main-chain polymers) [8-10]. Guest/host polymers blend NLO chromophores (guest) to the polymer matrices (host). They can achieve a higher noncentral symmetry through poling, but are prone to phase separation [11]. Sideand main-chain polymers bond the NLO chromophores to the polymer chains covalently and exhibit good phase mixing. However, the mobility of the polymer chain hinders the alignment of NLO chromophores, influencing the efficiency of electric field poling $[12,13]$. Crosslinking of the polymer which contains chromophore groups [14-16] or formation of interpenetrating polymer networks $[17,18]$ has been developed to reduce the mobility of the polymer segments; consequently, the materials require longer poling times and larger poling voltages $[19,20]$.

Disperse red 1 (DR1, Figure 1(a)) is very promising as NLO chromophore, because it is easy to create polar order of them by external electric field poling. To improve its processing and application characteristics, most studies have focused on the blending or covalent bonding methods to import it into the polymer [21-24]. Cui et al. [22] used a sol-gel process to copolymerize alkoxysilane dye and DR1 to prepare organic-inorganic hybrid materials. Aldea et al. [23] used the layer-by-layer electrostatic self-assembly structure to create multilayer thin film-based NLO materials. Tu et al. [24] explored the dynamic molecular behavior for mixing DR1 and poly(methyl methacrylate).

Spiropyran (SP, Figure 1(b)) plays a critical role in the photochromism field because the colorless SP form will 


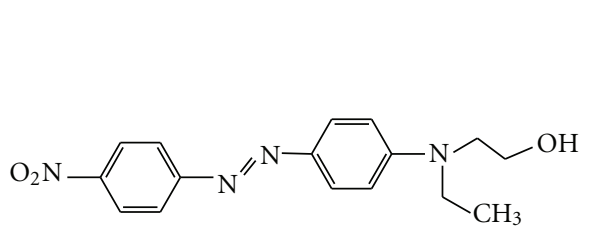

(a)

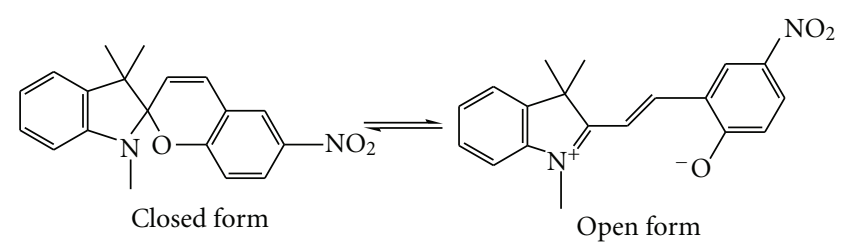

(b)

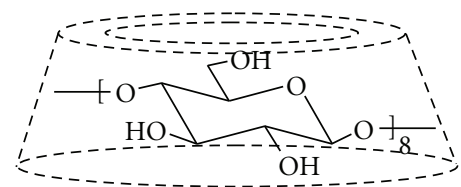

(c)

FIgURE 1: Schematic structures for (a) DR1, (b) SP, and (c) $\gamma$-CDP.

convert to a red-colored photomerocyanine (PM) under ultraviolet (UV) irradiation. The PM form can revert to the SP form either thermally or photochemically [25-27]. Typically, $\mathrm{SP}$ is included in polymer matrices to obtain various forms of solid-state photochromic materials to extend its commercial application range [28-30]. Kim et al. [28] prepared a series of cationic polymers using spirooxazines as side-chain groups. All of these synthesized photochromic polymer materials, whether in solution phase or solid-state thin films, have good photochromic properties.

Photomerocyanine (PMs) are comprised of strong electron donor and acceptor groups connected by a $\pi$-conjugated bridge. They possess delocalized $\pi$-electron systems capable of exhibiting charge transfer resonances, which leads to a preferential orientation of the molecules along the applied electric field [31-33]. Experimental values of dipole moments and first-order hyperpolarizability $\beta$ were reported for various PMs [34-37]. Replacing the benzopyryl moiety by $1,3-$ diethylthiobarbituric acid, the indoline-based PM exhibits a negative $\beta$ value $\left(\beta=-46 \times 10^{-30}\right.$ esu $)$ and a dipole moment of $7.4 \times 10^{-18}$ esu [34]. Theoretically, considerable efforts have been directed toward the molecular engineering of such chromophore structures [38-40]. We used the density functional theory (DFT) calculation [41-43], CAMB3LYP/6-31+G(d,p), and found that PM has a high dipole moment of approximately $2.8 \times 10^{-30}$ esu and shows high second-order NLO properties with first hyperpolarizability of approximately $38.4 \times 10^{-30}$ esu (commonly used stilbeneseries NLO molecules are approximately $7 \times 10^{-30} \sim 38 \times$ $10^{-30}$ ). Because colorless SP form does not have NLO properties, different optical wavelengths can convert it between the two forms and produce second-order NLO property changes that can be applied to photocontrollable components for data storage or optooptical switching [44].

Therefore, this study uses the inclusion complex method to separately import DR1 and SP into the $\gamma$-cyclodextrin $(\gamma$-CD) cavity of $\gamma$-cyclodextrin polymer $(\gamma$-CDP, Figure $1(\mathrm{c}))$ to prepare DR $1 / \gamma$-CDP and SP $/ \gamma$-CDP complexes for nonphotocontrollable and photocontrollable NLO polymers. Incorporation of chromophore in the cavity of $\gamma$-CDP increases the free volume surrounding the chromophore and decreases the spatial constraint from polymer chains. Additionally, the physical bonding between chromophore and $\gamma$-CDP enables the materials to simultaneously possess the guest/host NLO material's advantage of being simple to prepare and easy to polarize and the covalently linked NLO material's advantage of having a stable phase mixing structure.

\section{Experimental}

2.1. Preparation of Inclusion Complexes. $\mathrm{N}$-Ethyl- $\mathrm{N}-(2-$ hydroxyethyl)-4-(4-nitrophenylazo)aniline (Disperse red1, DR1) and $\gamma$-cyclodextrin polymer $(\gamma$-CDP) were purchased from Sigma-Aldrich, and $1^{\prime}-3^{\prime}-3^{\prime}$-Trimethyl-6-nitrospiro [2H-1-benzopyran-2,2' -indoline] (Spiropyran, SP) was purchased from TCI, respectively, and used as received. Solutions $\left(250 \mu \mathrm{L}, 1 \times 10^{-2} \mathrm{M}\right)$ of DR1 and SP in ethanol were injected separately into $5 \mathrm{~mL}$ of aqueous $\gamma$-CDP $\left(1 \times 10^{-2} \mathrm{~mol} \gamma-\mathrm{CD} / \mathrm{L}\right)$ solution at $30^{\circ} \mathrm{C}$ with sonication for $10 \mathrm{~min}[45,46]$. After $24 \mathrm{~h}$ of stirring, the DR $1 / \gamma$-CDP and $\mathrm{SP} / \gamma$-CDP inclusion complexes were deposited separately by spin coating onto ITO (indium tin oxide) glass plates and dried at $40^{\circ} \mathrm{C}$ in vacuo overnight for Ultraviolet/Visible (UV/VIS, Hitachi U-3900) analysis. Because of the extreme light sensitivity of SP, all operations for $\mathrm{SP} / \gamma$-CDP complex preparation must be conducted in a dark room.

To calculate the complex stoichiometry, solutions of DR1 and SP $\left(1 \times 10^{-5} \mathrm{M}\right)$ in ethanol were prepared separately. Samples of $0 \sim 7 \mathrm{~mL} \gamma$-CDP solution with concentrations of $1 \times 10^{-3} \mathrm{M}$ were added to each $1 \mathrm{~mL}$ sample of DR1 or SP solution. The samples were then diluted to $10 \mathrm{~mL}$ by adding water.

2.2. Poling Process. External electrical field (corona) poling was used to break the symmetry of the inclusion complex. The corona field between -3 and $-10 \mathrm{kV}$ was applied for $15 \mathrm{~min}$ after the film was heated to the desired temperature of approximately $150-200^{\circ} \mathrm{C}[14,24,47]$. Then the sample was cooled to room temperature under a continuous electrical field. During the poling procedure, the corona current was maintained at less than $50 \mu \mathrm{A}$, and the distance between 
the ITO and the needle was set at $1 \mathrm{~cm}$. For the SP $/ \gamma$-CDP complex, the poling process had to be conducted under the irradiation of UV light because a high dipole moment value only appears after the formation of the PM form. The changes in the UV/VIS spectroscopic absorbance were used to examine the alignment of the $\gamma$-CDP-complexed NLO chromophore (DR1 and SP) before and after poling by order parameter $\Phi[48]$ :

$$
\Phi=1-\left(\frac{A_{f}}{A_{o}}\right),
$$

where $A_{o}$ and $A_{f}$ are the UV/VIS absorbance for the polymer film before and after poling, respectively. After the oriented arrangement of molecules, the UV/VIS absorbance is reduced, causing the $\Phi$ value to increase.

2.3. Quantum Chemical Calculations. The geometries of complexed compounds were firstly optimized using Parameterized Model number 3 (PM3) [49], and then the twolayered hybrid ONIOM method [50], ONIOM(B3LYP/6$31 \mathrm{G}+(\mathrm{d}, \mathrm{p}): \mathrm{PM} 3)$, was adopted to find the ground-state geometry. The high-level layer, DR1 and SP, and the low-level layer, $\gamma$-CD, were calculated by B3LYP/6-31G+(d,p) and PM3, respectively. For comparison, B3LYP/6-31G+(d,p) and PM3 alone were also used to optimize the geometrical structures of isolated DR1 (or SP) and $\gamma$-CD, respectively. All calculations were made using the Gaussian09 program package [51].

\section{Results and Discussion}

3.1. Stoichiometry of Inclusion Complexes. The stoichiometry of the inclusion complex was determined using the BenesiHildebrand method [52-54] from the UV/VIS data:

$$
\frac{A_{0}}{\Delta A}=\frac{\left[1+1 /\left(\mathrm{K} \cdot[\gamma-\mathrm{CD}]^{n}\right)\right]}{(\Delta \varepsilon \cdot[\text { chromophore }])}
$$

where $\Delta A$ represents the difference between the absorptions of the chromophore (DR1 or SP) solution in the presence and absence $\left(A_{0}\right)$ of $\gamma$-CD; $\Delta \varepsilon$ denotes the difference between the molar absorption coefficients of chromophore $/ \gamma-\mathrm{CD}$ and chromophore; $n$ is the molar ratio of $\gamma$-CD to SP; and [chromophore] and $[\gamma-\mathrm{CD}]$ are the concentrations of chromophore and $\gamma-\mathrm{CD}$, respectively. The linear relationships of $\Delta A^{-1}$ against $[\gamma-\mathrm{CD}]^{-2}$ for both DR1 and SP reveal the formation of $1: 2 \mathrm{DR} 1 / \gamma-\mathrm{CD}$ and $1: 2 \mathrm{SP} / \gamma$-CD complexes (Figure 2).

Quantum chemical calculations by using the two-layered hybrid ONIOM method were performed for each of the complexes of interest to yield geometries (Figure 2 inset) and energies that were determined exclusively by the inclusion processes. The calculations of binding energies revealed that for both DR1 and SP, the $1: 2 \gamma$-CD inclusion complexes (22.6 and $15.4 \mathrm{kcal} \mathrm{mol}^{-1}$ for DR $1 / \gamma$-CD and SP $/ \gamma$-CD complexes, resp.) are more stable than the $1: 1 \gamma$-CD inclusion complexes (7.7 and $5.2 \mathrm{kcal} \mathrm{mol}^{-1}$ for DR $1 / \gamma$-CD and SP $/ \gamma$-CD complex, resp.). This result agrees with experimental UV/VIS analyses:

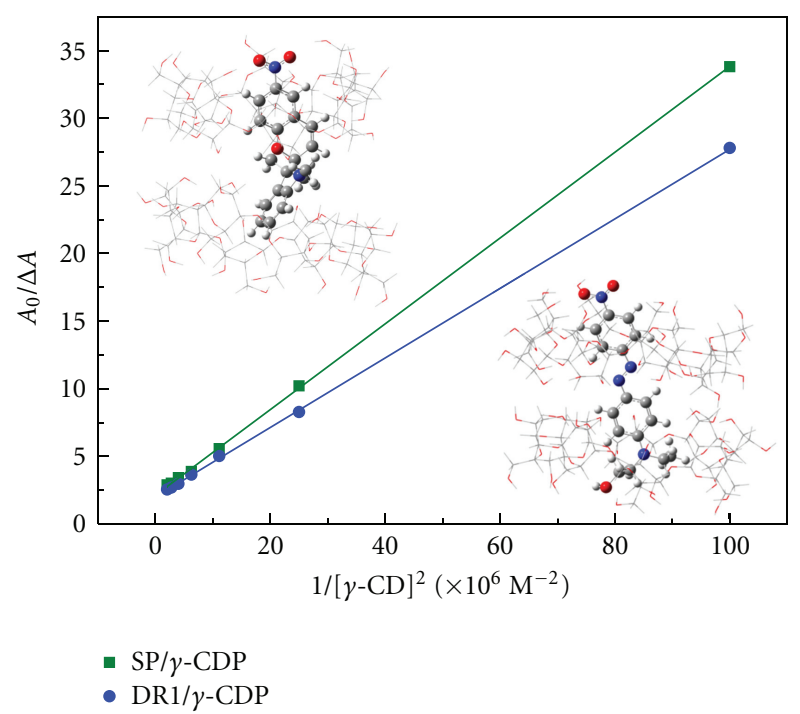

FIgURE 2: The linearity of the data when $1: 2$ complexation of DR $1: \gamma-C D$ and SP $: \gamma-C D$ is assumed. The insets show the optimized complexes.

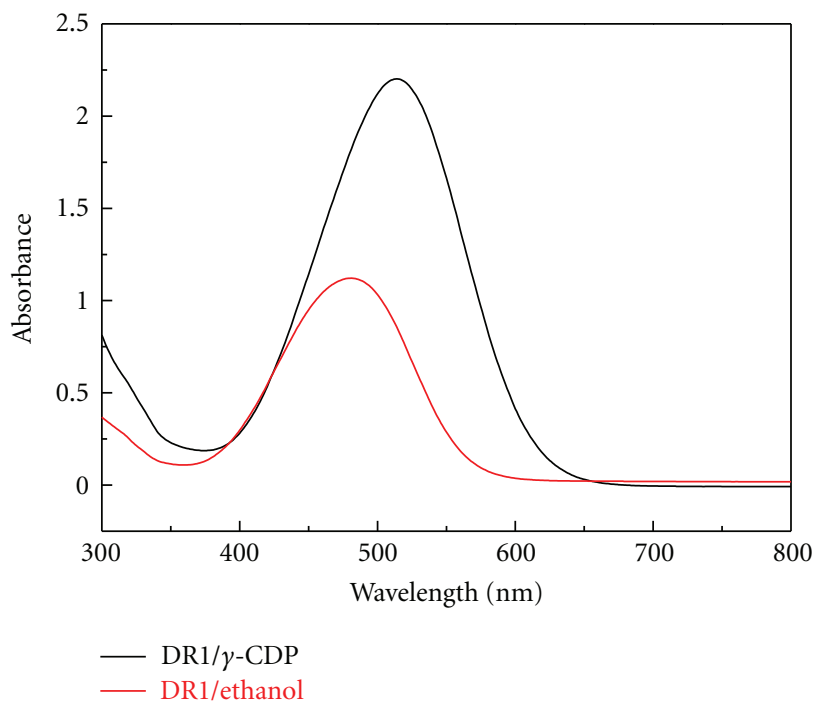

FIGURE 3: UV/VIS absorption spectra of DR1 in ethanol and in $\gamma$ CDP.

the hydrophobic $\gamma$-CD cavity encourages the end moieties of chromophore studied each entering one $\gamma$-CD cavity from the polar solvent.

3.2. Nonphotocontrollable NLO Materials. Figure 3 shows the UV/VIS spectra of DR1 in ethanol and in $\gamma$-CDP. After $\gamma$ CDP complexation, the absorption maxima of DR1 moved from $481 \mathrm{~nm}$ to $514 \mathrm{~nm}$, thereby confirming the formation of the DR $1 / \gamma$-CDP complex. The increase in absorption wavelength upon complexation is attributable to the interaction of DR1 and $\gamma$-CDP. To achieve an overall noncentrosymmetry, the corona poling method was used to enable the orderly alignment of DR1 through an external electric field. 


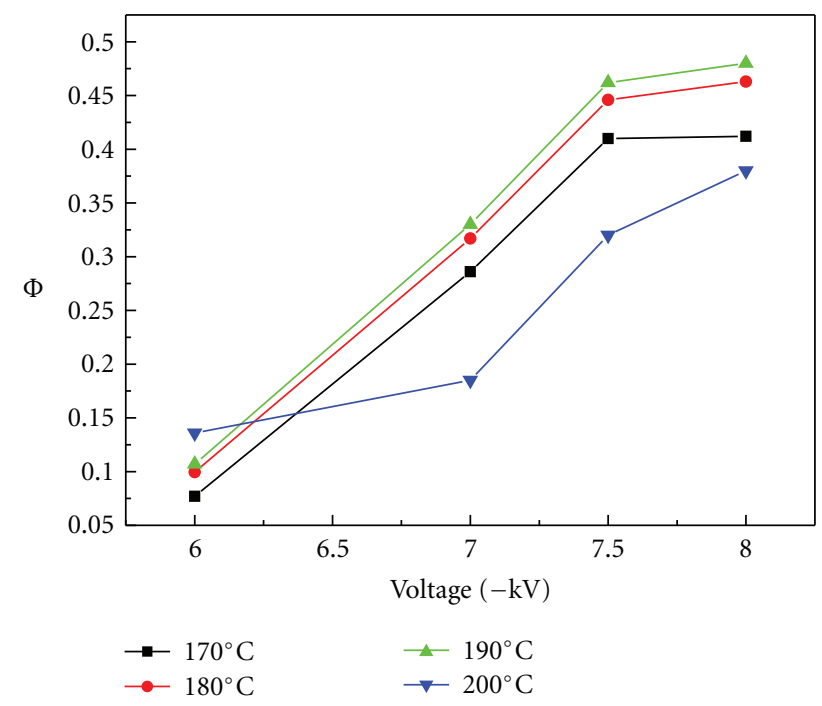

FIGURE 4: Effect of poling conditions on the order parameter $(\Phi)$ of DR $1 / \gamma$-CDP complex.

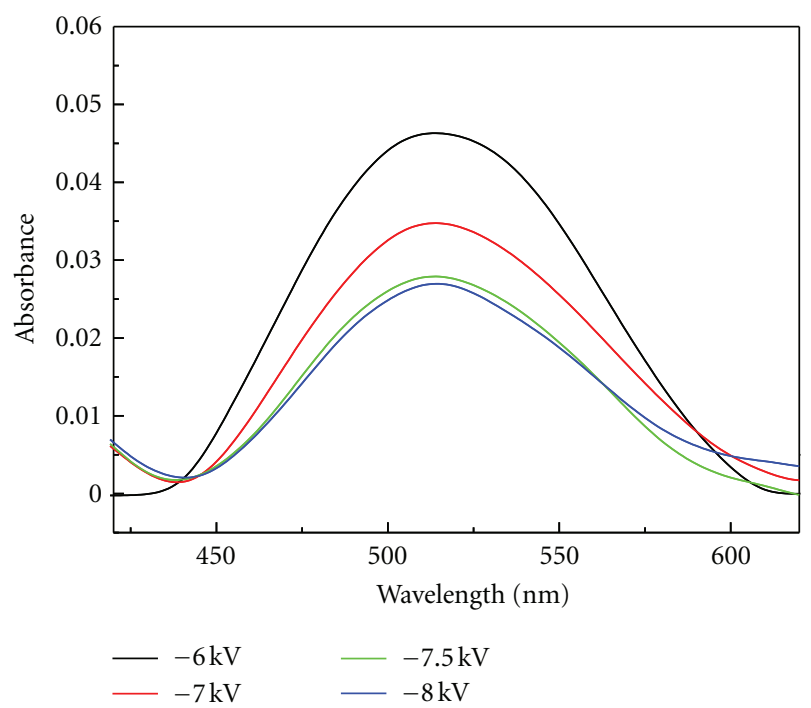

FIGURE 5: UV/VIS absorption spectra of DR $1 / \gamma$-CDP complex after electric-field poling.

The poling voltage $(-6.0,-7.0,-7.5$ and $-8.0 \mathrm{kV})$, temperature $\left(170,180,190\right.$, and $\left.200^{\circ} \mathrm{C}\right)$, and time $(15,25$ and $30 \mathrm{~min}$ ) were altered, respectively, to determine the optimal poling conditions. After the oriented arrangement of molecules, the UV/VIS spectrum exhibits a decrease in absorption through which the order parameter $(\Phi)$ of the poled film can be estimated. The experimental results indicate that the $\Phi$ value increases with the poling time until $15 \mathrm{~min}$. However, the $\Phi$ value was no longer affected after $15 \mathrm{~min}$.

Nevertheless, the poling voltage and temperature range used in this study have a significant impact on the $\Phi$ value (Figure 4). As the poling temperature is fixed, the UV/VIS absorbance is reduced significantly ( $\Phi$ value increased) with the increase of poling voltage (Figure 5), but the $\Phi$ value

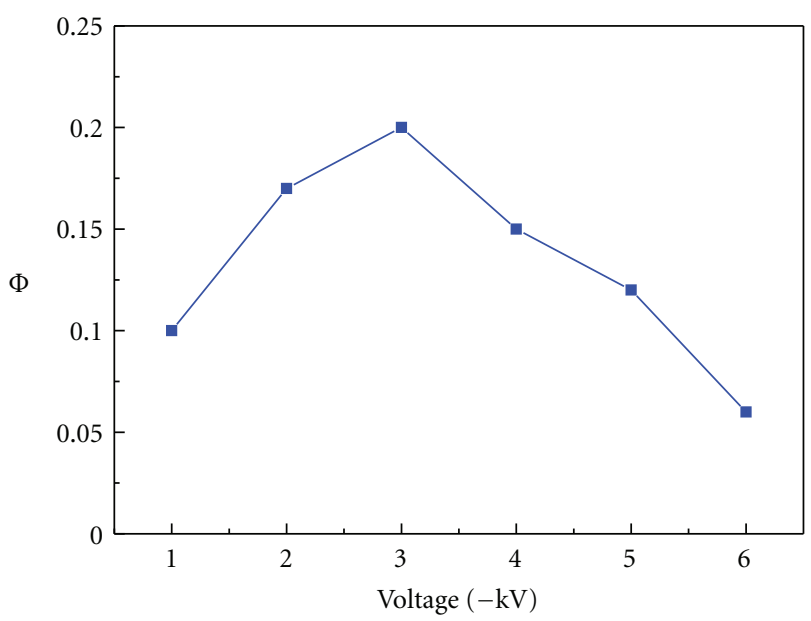

FIGURE 6: Order parameter $(\Phi)$ of $\mathrm{SP} / \gamma$-CDP complex at $150^{\circ} \mathrm{C}$.

increases only slightly after the poling voltage is increased to $-7.5 \mathrm{kV}$. At a fixed poling voltage (Figure 4 ), when the temperature increases from $170^{\circ} \mathrm{C}$ to $180^{\circ} \mathrm{C}$, the $\Phi$ value changes more significantly, increasing approximately $12 \%(-8.0 \mathrm{kV})$ to $29 \%(-6.0 \mathrm{kV})$. If the temperature continues to increase until $190^{\circ} \mathrm{C}$, the $\Phi$ value would increase accordingly (only slightly), at approximately $4 \%(-8.0 \mathrm{kV})$ to $8 \%(-6.0 \mathrm{kV})$. At a poling temperature of $200^{\circ} \mathrm{C}$, the largest $\Phi$ value is obtained at a low-voltage of $-6.0 \mathrm{kV}$, showing approximately twice the $\Phi$ value compared to other temperatures. However, the $\Phi$ value increased only slightly when the voltage continued to increase. The optimal operating conditions for DR $1 / \gamma$-CDP are $-8.0 \mathrm{kV} / 190^{\circ} \mathrm{C}$ to obtain an $\Phi$ value of 0.48 , which is higher than the $\Phi$ value between 0.16 and 0.30 for DR1 doped poly(methyl methacrylate) $[55,56]$.

3.3. Photocontrollable NLO Materials. The UV/VIS absorption spectra for the prepared $\mathrm{SP} / \gamma$-CDP inclusion complex indicate that, after SP was combined with $\gamma$-CDP, the absorption maximum of SP moved from $337 \mathrm{~nm}$ to $382 \mathrm{~nm}$, confirming the formation of the SP $/ \gamma$-CDP complex. The experimental results showed that the SP $/ \gamma$-CDP complex had a higher $\Phi$ value at a poling temperature of $150^{\circ} \mathrm{C}$. At this temperature, the $\Phi$ value increased with poling voltage increases from $-1.0 \mathrm{kV}$ to $-3.0 \mathrm{kV}$, but decreased as the poling voltage increased further from $-3.0 \mathrm{kV}$ to $-6 \mathrm{kV}$ (Figure 6). Among them, the poling voltage of $-3.0 \mathrm{kV}$ demonstrated the highest $\Phi$ value, at approximately 0.20 .

To clarify whether SP $/ \gamma$-CDP still retains photochromic properties after high voltage poling, the study applied repeated irradiation of $366 \mathrm{~nm}$ on the samples. The results indicated that after the materials absorbed UV light, a 568 absorption peak emerged, which was the absorption position of open-form PM. After the UV light was removed, the 568 absorption peak disappeared and the material returned to its original colorless state. Therefore, the $\mathrm{SP} / \gamma$-CDP retains photochromic properties after high voltage poling.

The $\Phi$ values of all poled polymer placed in a drying oven for 120 days under ambient temperature and atmospheric 


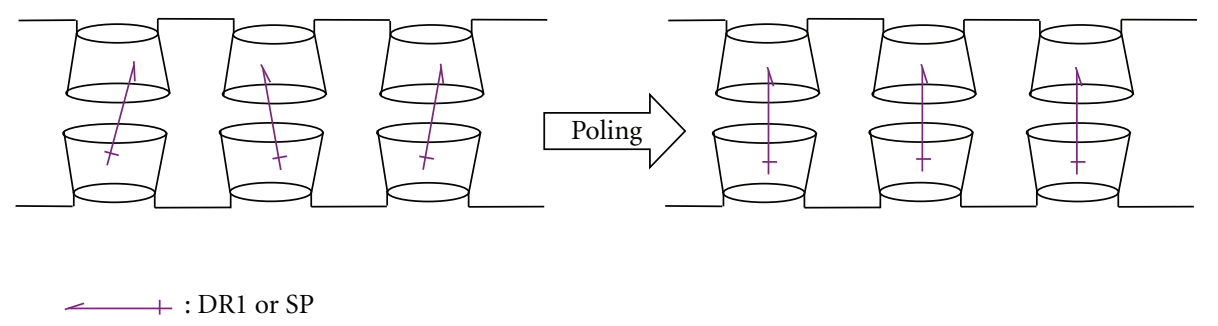

FIGURE 7: Schematics of aligned NLO chromophores in $\gamma$-CDP complexes.

pressure are maintained. This indicates that $\gamma$-CDP complexation produces excellent stability for the oriented arrangement of NLO chromophore. The hydrogen bonds between the hydroxyl groups laced on the rims of $\gamma$-CD increase the rigidity of the polymer chain preventing the relaxation of induced dipoles and further enhancing the stability of the poled complex (Figure 7). Additionally, the $\gamma$-CD cavity avoids the mobility of polymer segments interrupting the alignment of the NLO chromophore; therefore, the inclusioncomplexed DR1 and SP molecules are free to align themselves along an applied electric field.

\section{Conclusion}

Nonlinear optical polymers with oriented and orderly alignment have been prepared by forming inclusion complexes of disperse red 1 (DR1) and spiropyran (SP) in the $\gamma$ cyclodextrin cavity of $\gamma$-cyclodextrin polymer $(\gamma$-CDP). Among them, the SP $/ \gamma$-CDP complex retains photochromic properties after poling and can be applied in photocontrollable NLO materials. Consistent with experimental ultraviolet/visible (UV/VIS) spectra, quantum chemical calculations provided valuable insight into the possible $1: 2$ inclusion geometries and the relative stabilities of the DR $1 / \gamma-C D$ and $\mathrm{SP} / \gamma$-CD complexes. The UV/VIS spectral analyses demonstrate the correlation between poling voltage, poling temperature, poling time, and the NLO properties. The orderliness of the molecular alignment (order parameter $\Phi$ ) within the material is significantly affected by the poling voltage and temperature. Voltage has a more significant effect than temperature.

Increasing voltage between $-6.0 \mathrm{kV}$ and $-8.0 \mathrm{kV}$ increases the $\Phi$ value of DR $1 / \gamma$-CDP at a fixed temperature. At a fixed voltage, the $\Phi$ value increases with temperature at the ranges of $170^{\circ} \mathrm{C}$ and $190^{\circ} \mathrm{C}$. The highest $\Phi$ value of approximately 0.48 is obtained under the condition where the voltage is $-8.0 \mathrm{kV}$ and temperature is $190^{\circ} \mathrm{C}$. When the temperature is $200^{\circ} \mathrm{C}$, the $\Phi$ value obtained under the voltage of $-6.0 \mathrm{kV}$ is approximately double the $\Phi$ value obtained from any other temperatures. However, continued increases of voltage increments may cause material degradation.

$\mathrm{SP} / \gamma$-CDP still retains photochromic properties after high voltage poling, implying that $\gamma$-CDP provides adequate space to preserve the photochromic conversion of SP. The optimal operating conditions for $\mathrm{SP} / \gamma$-CDP are $-3.0 \mathrm{kV} / 150^{\circ} \mathrm{C}$ to obtain an $\Phi$ value of 0.20 . Materials maintained the same $\Phi$ value after poling for 120 days. This may be attributed to the fact that the $\gamma$-CDP forms extensive hydrogen bonds in adjacent $\gamma$-CD and thereby increases rigidity, preventing the relaxation of induced dipoles and allowing the achievement of a high degree of stability.

\section{Acknowledgments}

The authors would like to thank the National Science Council of Taiwan (Grant NSC 99-2221-E-242-001-) for financial support. Also, the computer time and facilities provided by the National Center for High-Performance Computing (NCHC) are highly appreciated.

\section{References}

[1] M. P. Balanay and D. H. Kim, "Optical properties of porphyrin analogues for solar cells: an NLO approach," Current Applied Physics, vol. 11, no. 1, pp. 109-116, 2011.

[2] L. R. Dalton, P. A. Sullivan, and D. H. Bale, "Electric field poled organic electro-optic materials: state of the art and future prospects," Chemical Reviews, vol. 110, no. 1, pp. 25-55, 2010.

[3] P. A. Sullivan and L. R. Dalton, "Theory-inspired development of organic electro-optic materials," Accounts of Chemical Research, vol. 43, no. 1, pp. 10-18, 2010.

[4] M. J. Cho, D. H. Choi, P. A. Sullivan, A. J. P. Akelaitis, and L. R. Dalton, "Recent progress in second-order nonlinear optical polymers and dendrimers," Progress in Polymer Science, vol. 33, no. 11, pp. 1013-1058, 2008

[5] E. Jecs, J. Kreicberga, V. Kampars, A. Jurgis, and M. Rutkis, "Novel azobenzene precursors for NLO active polyuretanes: synthesis, quantum chemical and experimental characterization," Optical Materials, vol. 31, no. 11, pp. 1600-1607, 2009.

[6] W. Shi, Z. Zhang, Q. Pan et al., "Nonlinear optical properties and chromophore electrostatic interactions for the poly(ether ketone) guest-host polymer films," Macromolecules, vol. 34, no. 6, pp. 2002-2007, 2001.

[7] W. J. Kuo, G. H. Hsiue, and R. J. Jeng, "Novel guest-host NLO poly(ether imide) based on a two-dimensional carbazole chromophore with sulfonyl acceptors," Macromolecules, vol. 34, no. 7, pp. 2373-2384, 2001.

[8] Z. Li, W. Wu, C. Ye, J. Qin, and Z. Li, "Two types of nonlinear optical polyurethanes containing the same isolation groups: syntheses, optical properties, and influence of binding mode," Journal of Physical Chemistry B, vol. 113, no. 45, pp. 14943-14949, 2009.

[9] P. A. Ribeiro, D. T. Balogh, J. L. C. Fonseca, and J. A. Giacometti, "Chromophore relaxation in a side-chain 
methacrylate copolymer functionalized with 4-[N-Ethyl$\mathrm{N}$-(2-hydroxyethyl)] ammo-2' -chloro- $4^{\prime}$-nitroazobenzene," Macromolecules, vol. 37, no. 7, pp. 2618-2624, 2004.

[10] M. Ronchi, A. O. Biroli, D. Marinotto, M. Pizzotti, M. C. Ubaldi, and S. M. Pietralunga, "The role of the chromophore size and shape on the SHG stability of PMMA films with embebbed NLO active macrocyclic chromophores based on a cyclotetrasiloxane scaffold," Journal of Physical Chemistry C, vol. 115, no. 10, pp. 4240-4246, 2011.

[11] K. H. Park, R. J. Twieg, R. Ravikiran et al., "Synthesis and nonlinear-optical properties of vinyl-addition poly(norbornene)s," Macromolecules, vol. 37, no. 14, pp. 5163-5178, 2004.

[12] Y. Zhang, J. Martinez-Perdiguero, U. Baumeister et al., "Laterally azo-bridged $\mathrm{H}$-shaped ferroelectric dimesogens for secondorder nonlinear optics: ferroelectricity and second harmonic generation," Journal of the American Chemical Society, vol. 131, no. 51, pp. 18386-18392, 2009.

[13] Z. Li, G. Yu, Y. Liu, C. Ye, J. Qin, and Z. Li, "Dendronized polyfluorenes with high azo-chromophore loading density: convenient synthesis and enhanced second-order nonlinear optical effects," Macromolecules, vol. 42, no. 17, pp. 6463-6472, 2009.

[14] C. Wang, C. Zhang, M. S. Lee, and L. R. Dalton, "Urethane-urea copolymers containing siloxane linkages: enhanced temporal stability and low optical loss for second-order nonlinear optical applications," Macromolecules, vol. 34, no. 7, pp. 2359-2363, 2001.

[15] P. H. Chang, H. C. Tsai, Y. R. Chen, J. Y. Chen, and G. H. Hsiue, "Thermal stability and structural characterization of organic/inorganic hybrid nonlinear optical material containing a two-dimensional chromophore," Langmuir, vol. 24, no. 20, pp. 11921-11927, 2008.

[16] J. A. F. Boogers, P. T. A. Klaase, J. J. de Vlieger, and A. H. A. Tinnemans, "Cross-linked polymer materials for nonlinear optics. 2. Polyurethanes bearing azobenzene dyes," Macromolecules, vol. 27, no. 1, pp. 205-209, 1994.

[17] P. Prêtre, U. Meier, U. Stalder et al., "Relaxation processes in nonlinear optical polymers: a comparative study," Macromolecules, vol. 31, no. 6, pp. 1947-1957, 1998.

[18] R. J. Jeng, C. C. Chang, C. P. Chen, C. T. Chen, and W. C. Su, "Thermally stable crosslinked NLO materials based on maleimides," Polymer, vol. 44, no. 1, pp. 143-155, 2003.

[19] H. S. Nalwa and S. Miyata, Nonlinear Optics of Organic Molecules and Polymers, CRC press, 1997.

[20] C. Zhang, C. Wang, L. R. Balten, H. Zhang, and W. H. Steier, "Progress toward device-quality second-order nonlinear optical materials. 4. a trilink high $\mu \beta$ NLO chromophore in thermoset polyurethane: a est-host approach to larger electrooptic coefficients," Macromolecules, vol. 34, no. 2, pp. 253-261, 2001.

[21] D. Möncke, G. Mountrichas, S. Pispas, and E. I. Kamitsos, "Orientation phenomena in chromophore DR1-containing polymer films and their non-linear optical response," Materials Science and Engineering B, vol. 176, no. 6, pp. 515-520, 2011.

[22] Y. Cui, M. Wang, L. Chen, and G. Qian, "Synthesis and spectroscopic characterization of an alkoxysilane dye containing C. I. Disperse Red 1," Dyes and Pigments, vol. 62, no. 1, pp. 43-47, 2004.

[23] G. Aldea, H. Gutiérrez, J. M. Nunzi, G. C. Chitanu, M. Sylla, and B. C. Simionescu, "Second harmonic generation diagnostic of layer-by-layer deposition from Disperse Red 1-functionalized maleic anhydride copolymer," Optical Materials, vol. 29, no. 12, pp. 1640-1646, 2007.

[24] Y. Tu, Q. Zhang, and H. Ågren, "Electric field poled polymeric nonlinear optical systems: molecular dynamics simulations of poly(methyl methacrylate) doped with disperse red chromophores," Journal of Physical Chemistry B, vol. 111, no. 14, pp. 3591-3598, 2007.

[25] K. Kinashi, Y. Ono, Y. Naitoh, A. Otomo, and Y. Ueda, “Timeresolved fluorescence study on the photomerocyanine form of spiropyran and its derivative with azobenzene," Journal of Photochemistry and Photobiology A, vol. 217, no. 1, pp. 35-39, 2011.

[26] S. V. Paramonov, V. Lokshin, and O. A. Fedorova, "Spiropyran, chromene or spirooxazine ligands: insights into mutual relations between complexing and photochromic properties," Journal of Photochemistry and Photobiology C, vol. 12, no. 3, pp. 209-236, 2011.

[27] S. Kumar, K. Velasco, and A. McCurdy, "X-ray, kinetics and DFT studies of photochromic substituted benzothiazolinic spiropyrans," Journal of Molecular Structure, vol. 968, no. 1-3, pp. 13-18, 2010.

[28] S. H. Kim, S. Y. Park, C. J. Shin, and N. S. Yoon, "Photochromic behaviour of poly[N,N-[(3dimethylamino)propyl]methacrylamide] having spiroxazine pendant group," Dyes and Pigments, vol. 72, no. 3, pp. 299-302, 2007.

[29] Z. S. Fu, B. B. Sun, J. Chen, and L. Yuan, "Preparation and photochromism of carboxymethyl chitin derivatives containing spirooxazine moiety," Dyes and Pigments, vol. 76, no. 2, pp. 515-518, 2008.

[30] A. Yamano and H. Kozuka, "Perhydropolysilazane-derived silica-polymethylmethacrylate hybrid thin films highly doped with spiropyran: effects of polymethylmethacrylate on the hardness, chemical durability and photochromic properties," Thin Solid Films, vol. 519, no. 6, pp. 1772-1779, 2011.

[31] L. Sanguinet, J. L. Pozzo, M. Guillaume et al., "Acidoswitchable NLO-phores; benzimidazolo[2,3-b]oxazolidines," Journal of Physical Chemistry B, vol. 110, no. 22, pp. 10672-10682, 2006.

[32] L. Sanguinet, J. L. Pozzo, V. Rodriguez et al., "Acido- and phototriggered NLO properties enhancement," Journal of Physical Chemistry B, vol. 109, no. 22, pp. 11139-11150, 2005.

[33] Y. Atassi, J. A. Delaire, and K. Nakatani, "Coupling between photochromism and second-harmonic generation in spiropyran- and spirooxazine-doped polymer films," Journal of Physical Chemistry, vol. 99, no. 44, pp. 16320-16326, 1995.

[34] R. Ortiz, S. R. Marder, L. T. Cheng, B. G. Tiemann, S. Cavagnero, and J. W. Ziller, "The dependence of the molecular first hyperpolarizabilities of merocyanines on ground-state polarization and length," Journal of the Chemical Society, Chemical Communications, no. 19, pp. 2263-2264, 1994.

[35] G. J. Smith, A. P. Middleton, D. J. Clarke et al., "The effect of solvent on the excited vibronic states and first hyperpolarizability of "push-pull" merocyanines," Optical Materials, vol. 32, no. 9, pp. 1237-1243, 2010.

[36] C. J. Wyss, G. J. Smith, A. D. Woolhouse et al., “The firstorder hyperpolarizabilities of some charge transfer conjugated molecules with high transmission in the far red," Optical Materials, vol. 16, no. 3, pp. 341-347, 2001.

[37] M. E. Reish, A. J. Kay, A. Teshome, I. Asselberghs, K. Clays, and K. C. Gordon, "Testing computational models of hyperpolarizability in a merocyanine dye using spectroscopic and DFT 
methods," Journal of Physical Chemistry A, vol. 116, no. 22, pp. 5453-5463, 2012.

[38] C. Z. Zhang, H. Cao, C. Im, and G. Y. Lu, "Theoretical study of nonlinear optical properties of "parallel connection" chromophores containing parallel nonconjugated D- $\pi$ A units," Journal of Physical Chemistry A, vol. 113, no. 44, pp. 12295-12303, 2009.

[39] F. Momicchioli, G. Ponterini, and D. Vanossi, "First- and second-order polarizabilities of simple merocyanines. An experimental and theoretical reassessment of the two-level model," Journal of Physical Chemistry A, vol. 112, no. 46, pp. 11861-11872, 2008.

[40] Z. Sainudeen and P. C. Ray, "Nonlinear optical properties of zwitterionic merocyanine aggregates: role of intermolecular interaction and solvent polarity," Journal of Physical Chemistry A, vol. 109, no. 40, pp. 9095-9103, 2005.

[41] A. D. Becke, "Density-functional thermochemistry. III. The role of exact exchange," The Journal of Chemical Physics, vol. 98, no. 7, pp. 5648-5652, 1993.

[42] C. Lee, W. Yang, and R. G. Parr, "Development of the ColleSalvetti correlation-energy formula into a functional of the electron density," Physical Review B, vol. 37, no. 2, pp. 785-789, 1988.

[43] B. Miehlich, A. Savin, H. Stoll, and H. Preuss, "Results obtained with the correlation energy density functionals of becke and Lee, Yang and Parr," Chemical Physics Letters, vol. 157, no. 3, pp. 200-206, 1989.

[44] J. A. Delaire and K. Nakatani, "Linear and nonlinear optical properties of photochromic molecules and materials," Chemical Reviews, vol. 100, no. 5, pp. 1817-1845, 2000.

[45] S. X. Zhang, M. G. Fan, Y. Y. Liu, Y. Ma, G. J. Zhang, and J. N. Yao, "Inclusion complex of spironaphthoxazine with $\gamma$ cyclodextrin and its photochromism study," Langmuir, vol. 23, no. 18, pp. 9443-9446, 2007.

[46] C. Elsässer, A. Vüllings, M. Karcher, and P. Fumagalli, "Photochromism of spiropyran-cyclodextrin inclusion complexes on Au(111)," Journal of Physical Chemistry C, vol. 113, no. 44, pp. 19193-19198, 2009.

[47] M. He, T. Leslie, S. Garner, M. DeRosa, and J. Cites, "Synthesis of new electrooptic chromophores and their structure-property relationship," Journal of Physical Chemistry B, vol. 108, no. 25, pp. 8731-8736, 2004.

[48] Z. Li, W. Wu, G. Yu et al., "Dendronlike main-chain nonlinear optical (NLO) polyurethanes constructed from "H"-type chromophores: synthesis and NLO properties," Applied Materials \& Interfaces, vol. 1, no. 4, pp. 856-863, 2009.

[49] P. J. Stephens, F. J. Devlin, C. F. Chabalowski, and M. J. Frisch, "A $b$ Initio calculation of vibrational absorption and circular dichroism spectra using density functional force fields," Journal of Physical Chemistry, vol. 98, no. 45, pp. 11623-11627, 1994.

[50] V. Ruangpornvisuti, "Recognition of carboxylate and dicarboxylates by azophenol-thiourea derivatives: a theoretical hostguest investigation," Journal of Molecular Structure, vol. 686, no. 1-3, pp. 47-55, 2004.

[51] M. J. Frisch, G. W. Trucks, H. B. Schlegel et al., Gaussian 09, Gaussian, Wallingford, UK, 2009.

[52] S. Prabhu, S. Saravanamoorthy, M. Ashok, and S. Velmathi, "Colorimetric and fluorescent sensing of multi metal ions and anions by salicylaldimine based receptors," Journal of Luminescence, vol. 132, no. 4, pp. 979-986, 2012.
[53] Y. L. Shen, S. H. Yang, L. M. Wu, and X. Y. Ma, "Study on structure and characterization of inclusion complex of gossypol/beta cyclodextrin," Spectrochimica Acta A, vol. 61, no. 6, pp. 1025-1028, 2005.

[54] A. K. Ghosh, A. K. Mukherjee, and S. Bagchi, "Absorption spectrophotometric study of molecular complexation of asphaltene with bromanil," Energy \& Fuels, vol. 23, no. 1, pp. 392-396, 2009.

[55] K. Aljoumaa, Y. Qi, J. Ding, and J. A. Delaire, "Synthesis and characterizations of highly fluorinated poly(arylene ether)s for quadratic nonlinear optics," Macromolecules, vol. 42, no. 23, pp. 9275-9288, 2009.

[56] M. Casalboni, F. Sarcinelli, R. Pizzoferrato, R. D’Amato, A. Furlani, and M. V. Russo, "Second-harmonic generation and absorption spectra of platinum organometallic complexes incorporated in PMMA films," Chemical Physics Letters, vol. 319, no. 1-2, pp. 107-112, 2000. 

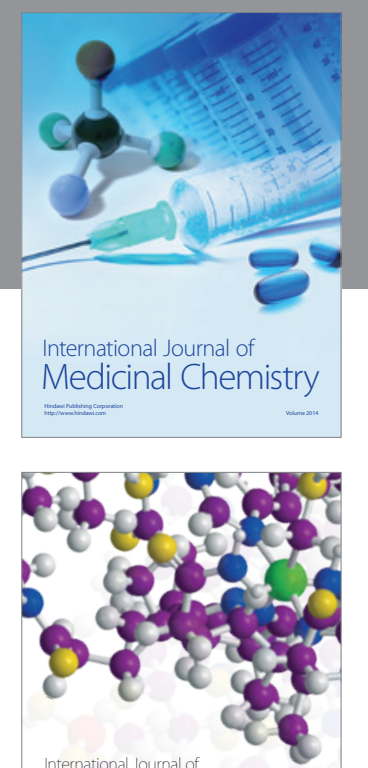

\section{Carbohydrate} Chemistry

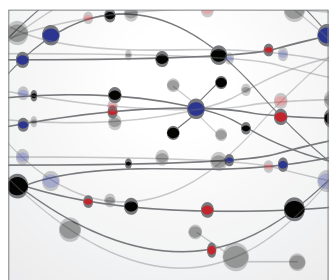

The Scientific World Journal
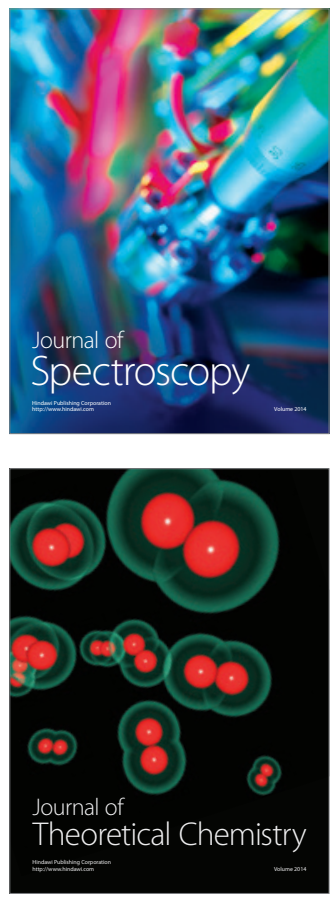
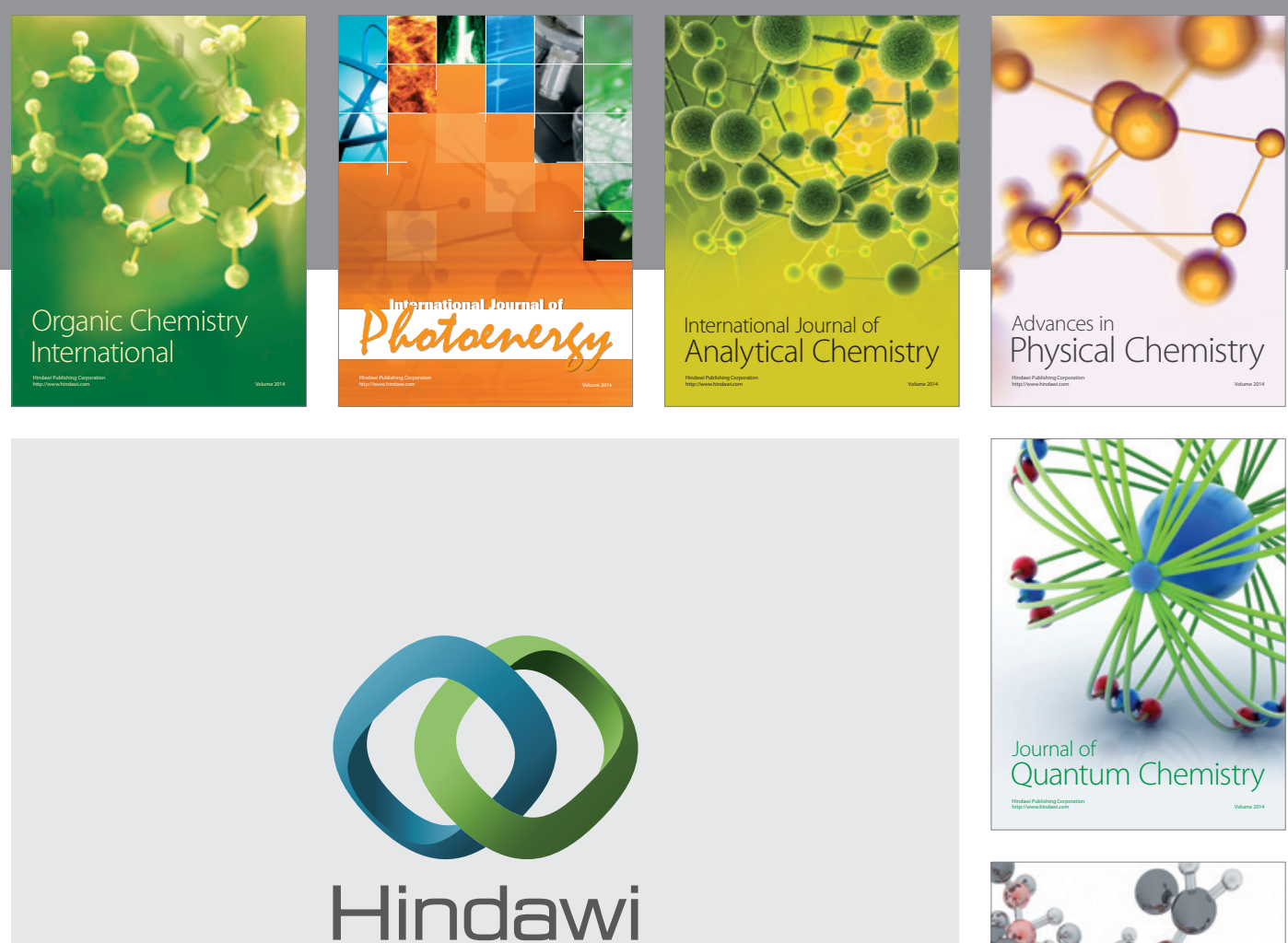

Submit your manuscripts at

http://www.hindawi.com

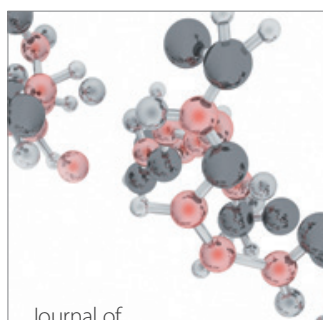

Analytical Methods

in Chemistry

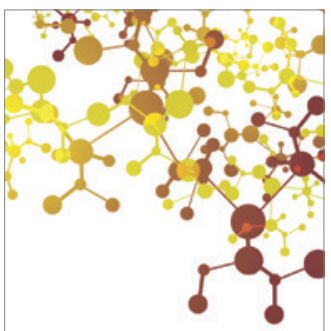

Journal of

Applied Chemistry

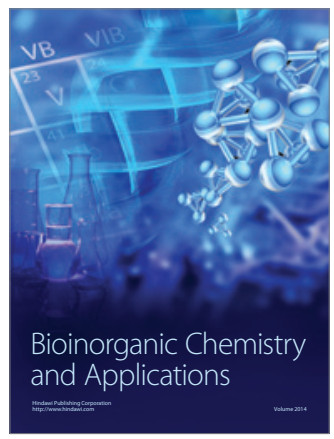

Inorganic Chemistry
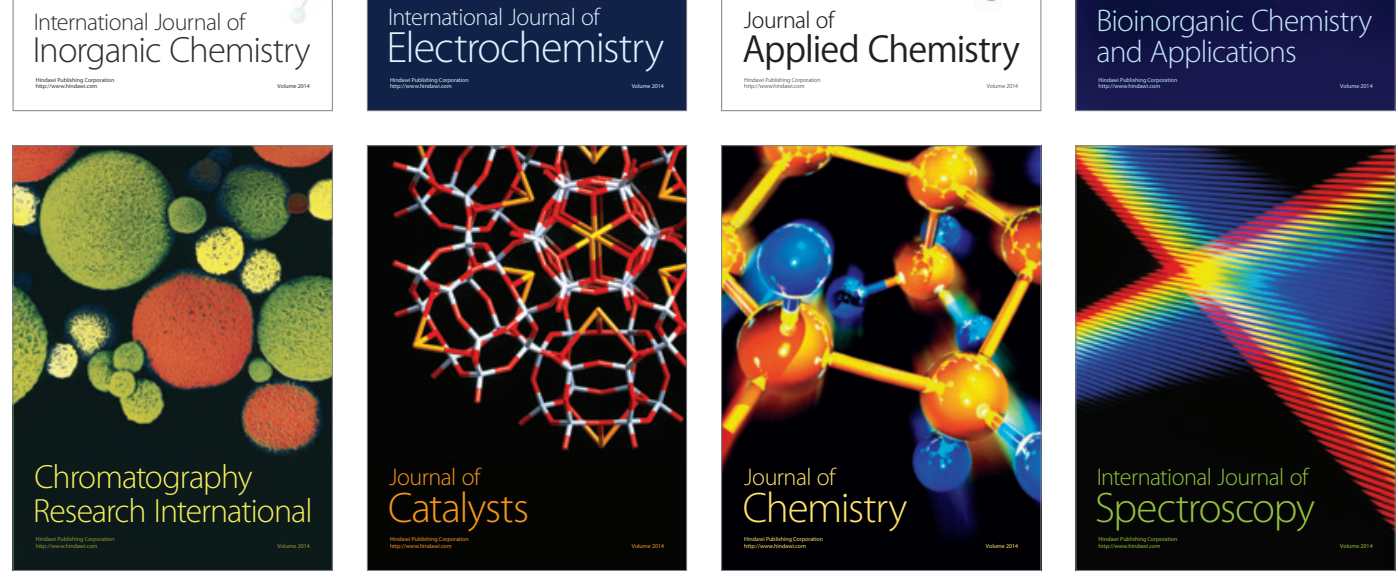